natural science. These successes led to the offer of a post on the staff of the University Tutorial College, where he went to teach biology and also geology to students at Red Lion Square working for the University of London examinations. While there he took his B.Sc. degree in 1890 with first-class honours in zoology and was first in the second class in honours in geology. He also obtained the fellowship diploma of the College of Preceptors with honours in two subjects and gained the Doreck Scholarship for theory and practice of education, thus getting in front of university teachers in their own examination.

His career as a professional teacher came to an end in 1893 with another breakdown of health. It was then that he began to earn his living by writing articles for the periodical press on common subjects in his own whimsical vein of reactions to them. His "Select Conversations with an Uncle" (1895) is a collection of such contributions from scores of other unsigned articles and tales. He also contributed a number of reviews to Nature, including one on Podmore's "Apparitions and Thought Transference". His first book was, however, Part 1 of a "Text-book of Zoology" (1893), with an introduction by G. B. Howes, assistant professor of zoology at the Royal College of Science, followed two years later by Part II, and Gregory and Wells's "Honours Physiography". In the same year (1895) "The Time Machine" was published, and Wells found himself recognized, at twenty-nine years of age, as a bright star rising above the horizon of the world of letters to radiate a new penetrating light before men.

The honorary degree of D.Lit. was conferred upon Wells by the University of London in 1936 ; and in 1943 he was awarded the D.Sc. degree for a thesis on "The Quality of Illusion in the Continuity of the Individual Life in the Higher Metazoa, with Particular Reference to Homo sapiens". He was president of the Educational Science Section of the British Association at the Nottingham meeting in 1937, when he gave an address on "The Informative Content of Education", which led to the publication of two reports upon the subject by a research com. mittee of the Association. He was elected an honorary fellow of the Imperial College of Science and Technology in 1943, just fifty years after the publication of "The Time Machine", the first of the imposing series of works by which Wells became the greatest international scientific educator of his times.

\section{SEVENTY-FIFTH ANNIVERSARY OF THE CORDOBA OBSERVATORY}

\section{By Dr. E. GAVIOLA Director}

$\mathrm{T}$ HE Cordoba Observatory owes its creation to the happy and trustful collaboration between a great Argentine statesman, President Sarmiento, and a great American astronomer, Director Gould.

During the nineteenth century, astronomy endeavoured to take possession of the sky by making an inventory of its stars. Bessel demanded already in 1822 to know the precise position and brilliance of all stars down to the ninth magnitude. He himself measured the positions of 62,380 stars between $45^{\circ}$ north and $15^{\circ}$ south. Argelander extended the limits to $80^{\circ}$ north and $31^{\circ}$ south, adding 50,000 stars. The
English astronomer Carrington filled the gap at the north pole. In the south, the American naval officer Gilliss had made many observations at Santiago de Chile $(1849-52)$ between $-65^{\circ}$ and the south pole, but he died in 1865 and it was uncertain if and when the positions would be reduced and published. (They were in 1895 , adding 16,748 stars to the inventory.)

Gould felt it was his mission to fill the great southern gap. He wrote in 1865 to Sarmiento, then Argentine envoy in Washington, asking for permission and protection for leading an astronomical expedition to Cordoba, supported by the friends of science in Boston. Sarmiento offered more than was asked. But the expedition had to be delayed: Gould could not obtain sufficient private funds; the Argentine Government regretted not to be able to help much at that $\operatorname{tim} \theta$, on account of having all its energies devoted to the Paraguay War (1866).

Sarmiento became President in 1868 and in the following year Gould was invited to organise an Argentine National Observatory. Gould accepted promptly, ordered a fine 5-in. meridian circle from Repsold in Hamburg, and sailed for Cordoba in 1870. On his arrival he heard that the Franco-Prussian War was delaying his instrument in Hamburg. When it finally arrived in Rosario, it was held up again by a quarantine due to an epidemic of yellow fever. The "Uranometría Argentina", a census of all the nakedeye stars from $10^{\circ}$ north to the southern pole, owes its existence to these delays. It contains 7,756 stars down to the seventh magnitude.

Seventy-five years ago, on October 24, 1871, the Cordoba Observatory was solemnly and officially inaugurated with speeches by President Sarmiento, Secretary Avellaneda and Director Gould.

The planned observations with the meridian circle were begun in September 1873 and continued by Gould until 1885, when he considered his mission in Cordoba fulfilled and returned to the United States. The main fruits of this period were the "Zone Catalogue", published in 1884, containing 73,161 stars between $23^{\circ}$ and $80^{\circ}$ south and the "Argentine General Catalogue" (1886) of 33,500 southern stars measured repeatedly with the utmost precision. The gap in the southern skies had been closed and the Cordoba Observatory had won a place of honour in the annals of world astronomy.

Under the direction of John M. Thome, the meridian observations continued and led to new catalogues, but the main work of this period (1885-1908) is undoubtedly the monumental "Cordoba Durchmusterung". It contains 613,718 stars between $-22^{\circ}$ and the southern pole. Thome himself could not finish it. The first three parts were published by him, the fourth was completed by his successor, Charles D. Perrine, in 1914. The fifth was observed and reduced by José Tretter, appearing in print in 1932, twentyfour years after Thome's death.

The Cordoba Durchmusterung contains all the stars down to the tenth magnitude, and many even fainter (to mag. 11.5) observed with a 5-in. equatorial refractor. It is still to-day the basis for the identification of southern stars.

Thome undertook in 1890 to continue the series of catalogues known as the zones of the "Astronomische Gesellschaft" from $-22^{\circ}$ south. He measured with the meridian circle the positions of 44,000 stars $\left(-22^{\circ}\right.$ to $-37^{\circ}$ ) between 1891 and 1900 , but did not live to see the catalogues published. They appeared in 1913, 1914 and 1925. The La Plata Observatory has measured and published the zones $-47^{\circ}$ to $-72^{\circ}$. 


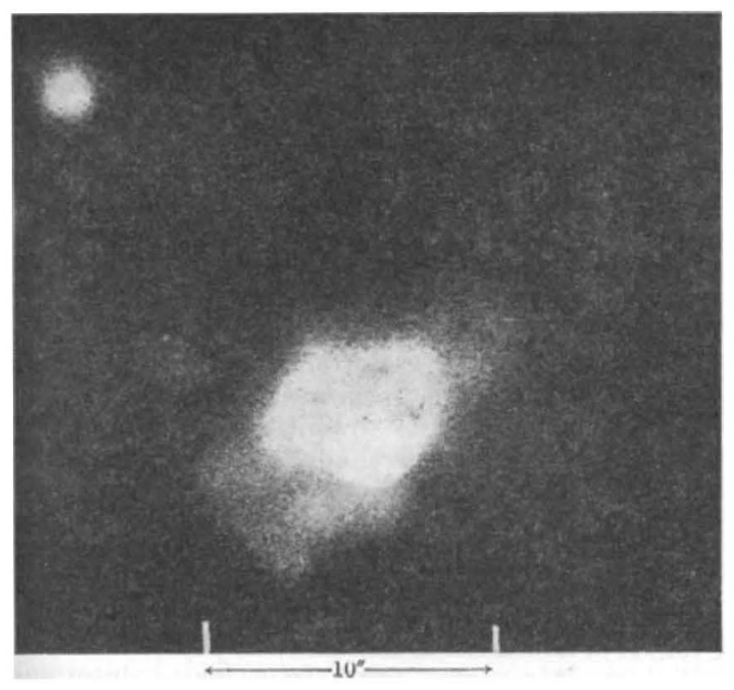

$\eta$ CARIN E. DIRECT PHOTOGRAPH TAKEN AT THE CASSEgRaIN FOCUS OF THE 60-IN. REFLECTOR OF THE CORDOBA OBSERVATORY WITH AN EQUIVAJENT FOCAL LENGTH OF 31.5 M. ENLARGET 20 TIMES FROM ORIGINAL. SCALE 10 ARO SEC. $=38$ MM. UPPER IEFT: FIELD STAR

The zone $-37^{\circ}$ to $-47^{\circ}$ has been reduced lately in Cordoba, and should appear in 1947. The zone $-82^{\circ}$ to $-90^{\circ}$ has been re-measured recently by Jorge Bobone with the 190-mm. Repsold meridian circle and is being reduced.

Cordoba has contributed to "La Carte du Ciel" with eight volumes published between 1925 and 1932, covering the zones $-24^{\circ}$ to $-31^{\circ}$. The work was begun by Thome but carried out mainly by Perrine.

The need of catalogues of high precision of a limited number of selected stars was met by Meade L. Zimmer, who measured, reduced and published the "First Fundamental Catalogue" in 1929 and the "General Fundamental Catalogue" in 1941. They contain 761 stars reduced to the mean equinoxes of 1900 and 1950 respectively.

Juan José Nissen, the first Argentine director of the Observatory, made an important contribution to the exact determination of the orbit of Eros, as part of the campaign led by the Astronomer Royal of Great Britain for the improvement of the solar parallax. The first places, according to statistical weights attributed to the results, were accorded to two southern observatories-the Cape and Cordobaamong thirty-six throughout the world.

When Perrine came to Cordoba in 1910 the 36-in. Crossley reflector at Lick Observatory and the 60-in. Ritchey reflector at Mount Wilson Observatory were opening new vistas to astrophysics. He obtained ample funds from the Argentine Government; he ordered a 60-in. mounting by Warner \& Swasey, moulded glass blanks by St. Gobain, and he built $a_{0}$ mechanical and an optical shop in Cordoba. Perrine desired to pioneer in stellar spectroscopy of the south as Gould did in astronomy. But the task of making large astronomical mirrors was beyond the skill of the personnel he could obtain at the time. The 60 -in. parabolic mirror was figured finally by Fecker in Pittsburgh in 1939; the Newtonian and Cassegrain secondaries by the optical shop of the Cordoba Observatory in 1941 and 1942.

The 154-cm. reflector was erected in Bosque Alegre, the Astrophysical Station of the Cordoba Observatory, and inaugurated in 1942.
A spectrograph with a dispersion of $40 \mathrm{~A}$. per mm. built in Cordoba, with a Wood grating, makes it possible to take spectra of stars down to the eleventh magnitude. A fast, 'nebular' spectrograph with a $60^{\circ}$ quartz prism and $f / 1$ Schmidt camera is being built.

Current work consists of the determination of radial velocities in the Magellanic Clouds (Ricardo Platzeck), the discovery and study of variable stars in the same (Martin Dartayet), investigation of spectroscopic binaries (Jorge Sahade), study of $\eta$ Carinæ and other stars with emission line spectra (Enrique Gaviola), theoretical astrophysics (Guido Beck), search for white dwarfs among stars of large proper motion (Martin Dartayet and David McLeish). Programmes of systematic determinations of radial velocities of southern stars are planned.

During the past seventy-five years astronomy has substantially completed the inventory of the sky. The intense and precise study of particular stars and phenomena, using the most refined methods of theoretical and experimental physics, is now demanding increasingly the attention of the astronomers. Cordoba hopes to be of service also in this new field.

\section{NEW DEVELOPMENTS IN RELATIV- ISTIC QUANTUM THEORY}

\author{
By DR. C. MØLLER
}

Institute for Theoretical Physics, Copenhagen

$T$ HE ordinary quantum mochanics which, in principle, was completed in the middle of the 'twenties, gives a correct account of a very large number of experimental results. Still, it was from th beginning quite clear that this theory is an approximation to the truth, since it does not satisfy the requirements of the theory of relativity. Nonrelativistic quantum mechanics would, therefore, be expected to give correct results only in those cases where the velocities of the elementary particles are small compared with the velocity of light.

However, at that time it was a general opinion among physicists that the adaptation of quantum mechanics to the requirements of relativity was more or less a mathematical question which would not give rise to any physical difficulties. In fact, Dirac was able to develop a relativistic theory of one electron in an external field; and this theory was in very good agreement with experiments also in cases where the velocity of the electron approaches the velocity of light.

Nevertheless, as one tried to give a relativistic treatment of the interaction between two or more elementary particles, one met with a characteristic difficulty which could not be removed in a satisfactory way by any mathematical trick. Since the development of the theory of relativity, the field concept had become of special importance in physics. In order to account for the finite propagation velocity of all forces, which is a fundamental consequence of the theory of relativity, it seemed absolutely necessary to describe the interaction between elementary particles by means of an intermediary field, and this field has to be treated as a special physical system in accordance with quantum mechanics.

This was done in 1929 for the first time by Heisenberg and Pauli in the case of electromagnetic forces 